\title{
EFFECT OF USING Er: YAG LASER TOOTH PREPARATION ON MICROLEAKAGE OF PORCELAIN LAMINATE VENEERS
}

\author{
Mohamed I.Ebrahim*, Alaa N Syam ${ }^{* *}$, Shukry G Mohamed***, \\ Ahmed M Hassan ${ }^{* * * *}$ and Weam Douidar ${ }^{* * * * *}$
}

\begin{abstract}
The Er: YAG laser was proven to successfully ablate enamel. This study was aimed to investigate the applicability of using this laser in preparing the enamel surface for porcelain laminate veneering in comparison with the high speed handpiece regarding the fracture strength loading of the veneers. Twenty human maxillary central incisors extracted were selected. They were divided into two equal groups [group I and group II], group I: High speed handpiece prepared specimens and group II: Er: YAG laser prepared specimens for measuring microleakage by a binocular stereomicroscope. The results of the microleakage assessment showed significant difference in the microleakage scores at the incisal margins of [Gr. I (group I)] the high speed handpiece compared to [Gr. II (group II)] the Er: YAG laser and significance comparing the microleakage scores at the cervical margins of both groups (Gr. I) and (Gr. II). Also, there were significant differences comparing incisal to those at the cervical margins of (Gr. I) the high speed handpiece, while in (Gr. II) the Er:YAG laser group, a marked significant difference were found between the microleakage scores at the incisal margins compared to the cervical margins.
\end{abstract}

Conclusion: The difference in microleakage assessment between laser and the high speed hand piece specimens was significant and affect the longevity of the porcelain laminate veneers.

\section{INTRODUCTION}

As we approach the twenty-first century, researchers in the dental field are faced with the challenge of mastering a rapidly changing technology. Exploring and understanding the possibilities will enable for a professional grow ${ }^{[1]}$.
Entry into the new millennium means adapting to this ever-changing technology, an evolution from simple mechanisms to the boundless era of electrooptics ${ }^{[2]}$.

Researches aimed to study the possible replacement of the bur drill by the laser to remove

\footnotetext{
* Assistant Professor of Dental Biomaterials, Faculty of Dental Medicine Al Azhar University, Cairo (Boy)

** Lecturre of Dental Biomaterials, Faculty of Dental Medicine Al Azhar University, Assuit Branch.

*** Lecturer of Pedodontic, Faculty of Dental medicine, Al Azhar University, Assuit Branch.

**** Assistant Professor of Restorative Dentistry, Alfarabi Colleges, Riyadh, KSA.

***** Lecturer of Restorative Dentistry, Faculty of Dentistry, Mansura University.
} 
caries, prepare cavities in enamel and dentin and condition the surface for a reliable restoration bonding. Also, reduce patient anxiety from the pain, noise and vibration of the mechanical drill ${ }^{[3]}$.

In dental research basic and clinical studies were done with the Er: YAG laser ${ }^{[4,5]}$. Comparative studies of pulpal reactions after caries removal and cavity preparation with Er: YAG laser and those with conventional high speed bur showed pulpal responses that were acceptable with no histo-pathological differences obtained between them. Studies on the ablated surface morphology by SEM, surface roughness, infrared spectroscopy, microleakage of applied restorations, and bond strength of resins, have made the Er:YAG laser challenging in replacing the high speed drill ${ }^{[6,7]}$.

Esthetic correction of anterior teeth has been achieved by the preparation of full crowns for many years, and was considered the most predictable and durable method. However, this approach is the most invasive with substantial removal of large amounts of sound tooth substance and possible adverse effects on adjacent pulp and periodontal tissues ${ }^{[8,9]}$.

Bonded ceramics were an exciting new entity for research and development since the 1980s, and now accepted as a valid treatment modality. Porcelain laminate veneers have exhibited predictability and experienced an incredibly rapid public acceptance with widespread utilization as one of the most conservative methods of restoring discolored, fractured, and malformed teeth with the least preparation thickness ${ }^{[10]}$.

Many studies had focused on the clinical efficiency of porcelain veneers, the tooth preparation design for porcelain veneers, the selection and type of the adhesive system, the quality of marginal adaptation, the resistance against microleakage, the periodontal response, the fracture resistance and the aesthetic characteristics of the restorations have been reviewed ${ }^{[11,12]}$.
Still little information about the evaluation of the applicability of the Er:YAG laser technique in teeth preparation compared by bur drilling in microleakage resistance and the fracture loading Strength of porcelain laminate veneers as well as the surface morphology with any expected compositional changes that might result ${ }^{[13-15]}$.

The objective of this study was to evaluate the effect of using Er: YAG laser tooth preparation on microleakage of porcelain laminate veneers

\section{MATERIAL AND METHODS}

The materials that were used in the current study are illustrated in table 1.

\begin{tabular}{|c|l|l|}
\hline 1 & \multicolumn{1}{|c|}{ Materials } & Trade/ Manufacturer \\
\hline 1 & $\begin{array}{l}\text { Impression material used: } \\
\text { Heavy and light body } \\
\text { (Additional -type silicone) } \\
\text { impression material (Putty Soft } \\
\text { +Dimension Grant L) }\end{array}$ & $\begin{array}{l}\text { Imprint II VPS, } \\
3 \mathrm{M} \text { ESPE Seefeld, } \\
\text { Germany }\end{array}$ \\
\hline 2 & $\begin{array}{l}\text { Stone type : (Type IV) dental } \\
\text { stone die material }\end{array}$ & $\begin{array}{l}\text { GC Fujirock, EP;GC } \\
\text { Corp, Tokyo, Japan) }\end{array}$ \\
\hline 3 & $\begin{array}{l}\text { Ceramic veneer type: Leucite- } \\
\text { reinforced glass-ceramic } \\
\text { material, }\end{array}$ & $\begin{array}{l}\text { IPS Empress } \\
\text { Ivoclar vivadent, } \\
\text { Schaan, Liechtenstein }\end{array}$ \\
\hline 4 & $\begin{array}{l}\text { Acid Etching \& Bonding : } \\
37 \% \text { phosphoric acid }\end{array}$ & $\begin{array}{l}\text { Total Etch;Ivoclar } \\
\text { Vivadent }\end{array}$ \\
\hline 5 & $\begin{array}{l}\text { Bonding agent: Syntac } \\
\text { bonding }\end{array}$ & $\begin{array}{l}\text { Syntac Primer and } \\
\text { Syntac adhesive; } \\
\text { Ivoclar Vivadent }\end{array}$ \\
\hline 6 & $\begin{array}{l}\text { Resin cement used } \\
\text { Transparent dual-polymerizing } \\
\text { (Variolink II) resin composite } \\
\text { of low viscosity }\end{array}$ & $\begin{array}{l}\text { Variolink II, Ivoclar } \\
\text { vivadent }\end{array}$ \\
\hline 7 Finishing disks \\
\hline
\end{tabular}

Sixty human maxillary central incisors extracted for periodontal causes with nearly the same crown length and mesio-distal width were selected. Teeth were free from dental caries or any restorations. Teeth were cleaned and stored in normal saline solution at room temperature immediately after extraction. 


\section{Grouping of samples:}

Teeth were divided into two equal groups according to preparation method used for laminate veneer; [group I and group II], group I: High speed handpiece prepared specimens (30 specimens) and group II: Er:YAG Laser prepared specimens (30 specimens) for measuring microleakage by a binocular stereomicroscope.

\section{Specimens and group preparations:}

A specially constructed mold to form resin blocks which consists of an inner split cylinder and an outer assembling one of $(1 \times 2 \times 1 \mathrm{~cm})$, the specimens were mounted individually in the acrylic blocks with their long axis perpendicular to the acrylic block surface. All specimens were embedded up to $2 \mathrm{~mm}$ below the cemento-enamel junction.

\section{Group I:}

Thirty central incisors were prepared in a window type preparation. The facial reduction was performed using self-limiting depth three-wheeldiamond of $0.5 \mathrm{~mm}^{*}$ to define the depth cuts, then a $1 \mathrm{~mm}$ chamfer diamond stone bur** ${ }^{* *}$ were used to refine the tooth preparation till the depth grooves as shown in figures (1). The gingival portion of the facial reduction ends with a chamfer finish line that ends $1 \mathrm{~mm}$ incisal to the cemento-enamel junction.

The facial reduction was extended proximally till the proximal line angles mesially and distally. The incisal edge was kept intact without an incisal overlap. All tooth preparation were completed entirely in enamel and finished without any sharp line angles. All the specimens were prepared using the high speed hand piece under water coolant.

\section{Group II:}

According to our pilot study made on five central incisors to standardize the technique of laser preparation, the proximal extensions and the laser parameters, energy used was $400-450 \mathrm{~mJ}$ at $250-350 \mu \mathrm{sec}$ at frequency of $10 \mathrm{~Hz}$, with an air water spray cooling system of $6 \mathrm{ml} / \mathrm{min}$. using the Er:YAG ${ }^{* * *}$ laser hand piece of spot size $0.63 \mathrm{~mm}$, figures (2). Three depth cuts similar to the limiting depth cutting three-wheel-diamond stone of $0.5 \mathrm{~mm}$ were prepared with the laser till the shank (of the three wheel stone stands steady on the unprepared enamel, Continuing preparation of all the enamel surface in a steady back and forth movement in a mesio-distal and inciso-cervical direction following the convexity of the tooth surface was done. The extension of facial reduction was similar to that of group I as a window type preparation extending proximally from the mesial to distal line angles and incisally to the incisal edge without an overlap and cervically ends $1 \mathrm{~mm}$ incisal to the cemento-enamel junction.

\section{Impression making and master die fabrication:}

Impression of the preparations was done by heavy and light body (Addition -type silicone) impression material; for each tooth impression was made separately in a specially designed perforated copper mold. The impressions were poured with a vacuum mixed improved (Type IV) dental stone die according to the manufacturer's instructions with respect to water/powder ratio and mixing time.

Dies were removed from the impressions, and 2 layers of die spacer* were painted $0.5 \mathrm{~mm}$ short of the finish lines of the preparations. Two coats of die lubricant ${ }^{* *}$ were then applied to each die.

\footnotetext{
* (834-31-021; Brasseler, Lemgo, Germany)

** (6844-314-014; Brasseler, Germany)

*** (Kavo KEY Er:YAG laser,Germany)

**** (Cement spacer, kerr dental, Orange, Calif.)

****** (Die lube; Degussa, south plainfield, N.J.)
} 


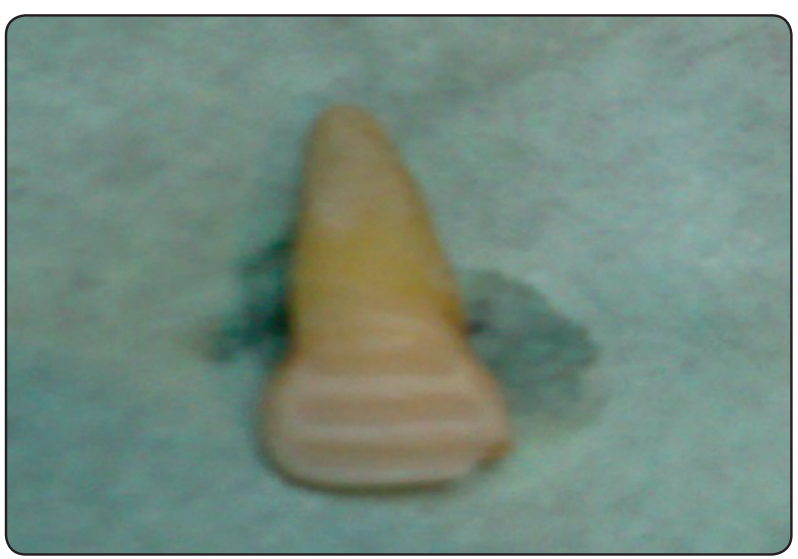

Fig (1): Photograph of central incisor from group I with indentations of the facial reduction using the selflimiting depth cutting disks.

\section{Ceramic Veneer fabrication:}

The Veneers were made of a leucite-reinforced glass-ceramic material, IPS Empress 1. All veneers were waxed then sprued. After investment of the wax patterns, the investment cylinders were preheated in a conventional preheating furnace (Kavo Dental Gmbh, Biberach, Germany) to a final temperature of $850{ }^{\circ} \mathrm{C}$. A hot press furnace (IPS Empress EP 5000 , Ivoclar Vivadent) was used for the pressing procedure of the ceramic veneers. The investment cylinders along with the glass-ceramic ingots were placed at the centre of the press furnace and pressed at a temperature of $1050{ }^{\circ} \mathrm{C}$.

After divestment, the pressed veneers were cut from the sprues with a water cooled diamond-coated disks (Diaflex, Horico Dental, Berlin, Germany) and cleaned with a jet steam machine (EV1, Sofia, Italy). The veneer fit was verified on the master casts. Two glazing procedures were performed in a porcelain firing oven (Programat P90/P95; Ivoclar Vivadent), (different IPS Empress ceramic veneers).

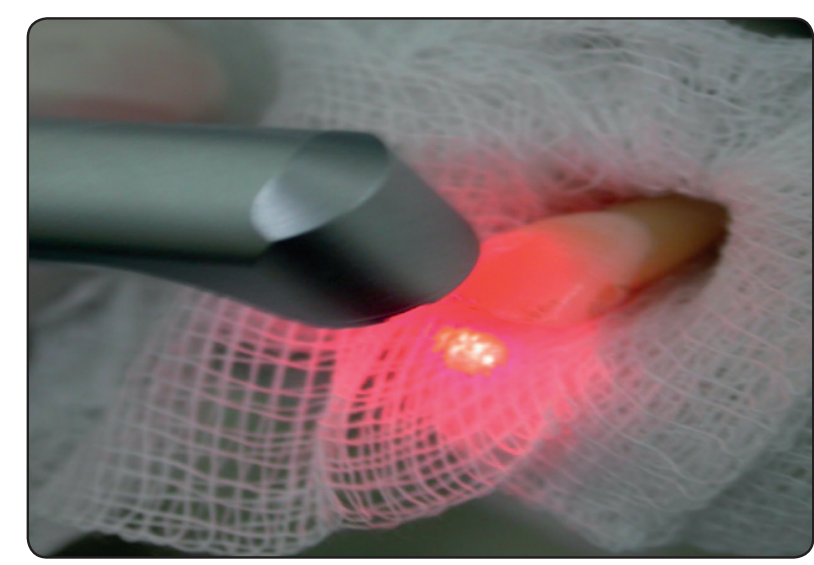

Fig (2): The Er:YAG laser ablation of enamel with the red aiming beam on the surface.

The intaglio surfaces of the veneer were airborneparticle abraded with a high-grade alumina* at 2-bar pressure and cleaned with a jet steam machine**.

\section{Acid etching:}

All teeth were cleaned, washed, dried, and then etched with $37 \%$ phosphoric acid for 15 seconds. After etching all teeth were rinsed with water spray, and dried with oil /water free air spray.

\section{Bonding the ceramic veneers:}

The veneers were cleaned with 99\% isopropanol, and the intaglio surface of the veneer was etched for 60 seconds with a 5\% hydrofluoric acid gel. A silane-coupling agent was then applied to the etched surface with a brush to the ceramic veneer for 60 seconds and air dried. The Syntac bonding was applied to the etched tooth surface, and the veneers were luted with a transparent dual-polymerizing resin composite*** of low viscosity.

The excess cement material was removed with sponge pellets while still soft, and the margins

\footnotetext{
* (Type 100, Kavo Dental GmbH)

** (SJ, Silfradent)

*** (Variolink II, Ivoclar vivadent)
} 
were covered with an air-inhibiting gel before light polymerizing. The ceramic veneers were light polymerized with the light cure system* from the facial to cervical and palatal for at least 60 seconds.

Finishing was performed using hand instruments (\# 15 scalpel, Bard-Parker) and the (Sof - Lex) finishing disks.

\section{Microleakage assessment:}

\section{Sealing of teeth:}

The root apices of the prepared samples were sealed with composite resin. Each tooth was then coated with clear nail polish except one millimeter away from the incisal and cervical edges. One layer of the polish is first applied by means of a soft gentle brush and left to dry, and then a second layer was applied to ensure complete sealing of all other surfaces of the tested specimens. Finally, a third layer of polish was applied, and while still tacky each tooth was wrapped individually with aluminum foil and adapted using a plastic instrument. After an hour $1 \mathrm{~mm}$ around the incisal and cervical margins of the foil was exposed with a sharp bard parker blade. A final coat of nail polish was then applied over the wrapped foil at the cut edges to ensure proper sealing.

\section{Preparation of tracing dye solution:}

A $2 \%$ aqueous solution of methylene blue dye was prepared by dissolving 2 grams of methylene blue powder in $100 \mathrm{ml}$ distilled water and the solution was properly agitated to ensure complete dissolution of powder particles.

\section{Immersion of teeth in the dye:}

The teeth were immersed in the $2 \%$ methylene blue dye solution for 4 hours period at room temperature then removed from the dye and rinsed thoroughly under running water for 5 minutes and the foil was stripped off, teeth cleaned softly and dried.

\section{Sectioning of the teeth:}

The teeth specimens with ceramics were sliced labiolingually into three equal slices using a watercooled 7/8 inch diamond disc rotating at low speed under sufficient water-cooling to avoid overheating and cracking.

\section{Microscopic assessment:}

A binocular stereomicroscope**, attached to a computer was used to investigate the extent of dye penetration at the incisal and cervical margins. Assessing microleakage was done with a scoring system as following:

- Score $0:$ No dye penetration at tooth /veneer interface

- Score 1 : Penetration of dye along incisal or cervical margins

- Score 2 : Penetration of the dye up to incisal or cervical one fourth of the tooth/ veneer Interface.

- Score 3: Penetration up to incisal or cervical half of the tooth/ veneer Interface.

- Score 4: Penetration of dye along the entire tooth/ veneer Interface.

The micrographs were examined and the microleakage score were observed. Results were statistically analyzed using the statistical package SPSS version 15 for windows, to analyze nonparametric test using the Chi-Square.

\footnotetext{
* (Elipar Free light 2, 3M, ESPE)

** (Leica, MZ6 Cold Light Germany)
} 


\section{RESULTS}

The results of the Chi-Square statistical analysis of the microleakage score of all the incisal specimens compared to all the cervical specimens without grouping, showed a significant difference, table (2). For more analyzing the data, the Mann-Whitney test was used to show any significant difference between the two groups and the four subgroups, table (3).

Table (3) shows the descriptive statistics of the microleakage scoring of the dye penetration through ceramic laminates at the incisal and the cervical margins for both groups. As analyzed, there were significant differences in the microleakage scores at the incisal margins of (Gr. I) the high speed handpiece compared to (Gr. II) the Er:YAG laser. Similar results were obtained with significance comparing the microleakage scores at the cervical margins of both groups (Gr. I) and (Gr. II).

The statistical analysis comparing the microleakage scores at the incisal to those at the cervical margins of (Gr. I) the high speed handpiece showed significant difference while in (Gr. II) the Er:YAG laser group, a marked significant difference were present between the microleakage scores at the incisal margins compared to the cervical margins.

The chart bar in figure (3) represents the difference in percentage of the microleakage scores between the incisal and cervical margins of the high speed handpiece group (Gr. I). the highest scoring percentage recorded in this group was $56.7 \%$ for score 2 at the cervical margins and also, $56.7 \%$ for score 1 at the incisal margins. While, the least scoring percentage recorded in this group was $10 \%$ for score 3 at the cervical margins.

The other chart bar in figure (4) represents the difference in percentage of the microleakage scores between the incisal and cervical margins of the Er:YAG laser group (Gr. II). The highest scoring percentage recorded in this group was $66.7 \%$ for score 2 at the incisal margins. While, the least scoring percentage recorded in this group was $6.7 \%$ for score 0 at the cervical margins.

The highest scoring percentage recorded was (66.7\% for score 2 at the incisal margins) of (Gr. II) the Er: YAG laser group, and the least scoring percentage recorded was $6.7 \%$ for score 0 at the cervical margins, also of (Gr. II) the Er: YAG laser group in figure (5). This result will explain the marked significant difference shown in the statistical analysis table (4) comparing the microleakage scores at the incisal margins to the cervical margins of the (Gr. II) the Er: YAG laser group.

TABLE (2): Chi-Square statistical analysis of the microleakage score of the total incisal compared to the total cervical marginal dye penetration.

\begin{tabular}{|l|c|c|c|c|c|c|c|}
\hline & 0 & 1 & 2 & 3 & Observed N & Chi-Square & P-value \\
\hline Incisal & 0 & 18 & 32 & 10 & 60 & 27.934 & 0.01 \\
\hline Cervical & 8 & 19 & 30 & 3 & 60 & 28.933 & 0.0001 \\
\hline Total & 8 & 37 & 62 & 13 & 120 & 56.867 & 0.0001 \\
\hline
\end{tabular}

$(P<0.05)$ significant; not significant $(P>0.05)$ 
TABLE (3): Descriptive statistics of the microleakage scoring of dye penetration through ceramic laminates at the incisal and the cervical margins for both high speed (Gr.I) and Er:YAG laser (Gr.II) groups using the Mann-Whitney Test.

\begin{tabular}{|c|c|c|c|c|c|c|}
\hline & & & Number & Mean Rank & Sum of ranks & $\mathrm{P}$ value \\
\hline \multirow[t]{3}{*}{ Incisal } & \multirow[t]{3}{*}{ Dye penetration score } & Gr.I & 30 & 33.15 & 814.5 & \multirow{3}{*}{0.001 significant } \\
\hline & & Gr.II & 30 & 22.85 & 1015.5 & \\
\hline & & Total & 60 & & & \\
\hline \multirow[t]{3}{*}{ Cervical } & \multirow[t]{3}{*}{ Dye penetration score } & Gr.I & 30 & 29.28 & 998.5 & \multirow{3}{*}{0.003 significant } \\
\hline & & Gr.II & 30 & 17.72 & 831.5 & \\
\hline & & Total & 60 & & & \\
\hline
\end{tabular}

$(P<0.05)$ significant; not significant $(P>0.05)$

TABLE (4): Descriptive statistics of the microleakage scoring of dye penetration through ceramic laminates at the incisal and the cervical margins for both high speed (Gr.I) and Er:YAG laser (Gr.II) groups.

\begin{tabular}{|c|c|c|c|c|c|c|}
\hline & & & Number & Mean Rank & Sum of ranks & $P$ value \\
\hline \multirow[t]{3}{*}{ Gr.I } & \multirow[t]{3}{*}{ Dye penetration score } & Incisal & 30 & 30.05 & 901.5 & \multirow[t]{3}{*}{0.002 significant } \\
\hline & & Cervical & 30 & 30.95 & 928.5 & \\
\hline & & Total & 60 & & & \\
\hline \multirow[t]{3}{*}{ Gr.II } & \multirow[t]{3}{*}{ Dye penetration score } & Incisal & 30 & 36.38 & 1091.5 & \multirow[t]{3}{*}{0.003 significant } \\
\hline & & Cervical & 30 & 24.62 & 738.5 & \\
\hline & & Total & 60 & & & \\
\hline
\end{tabular}

$(P<0.05)$ significant; not significant $(P>0.05)$

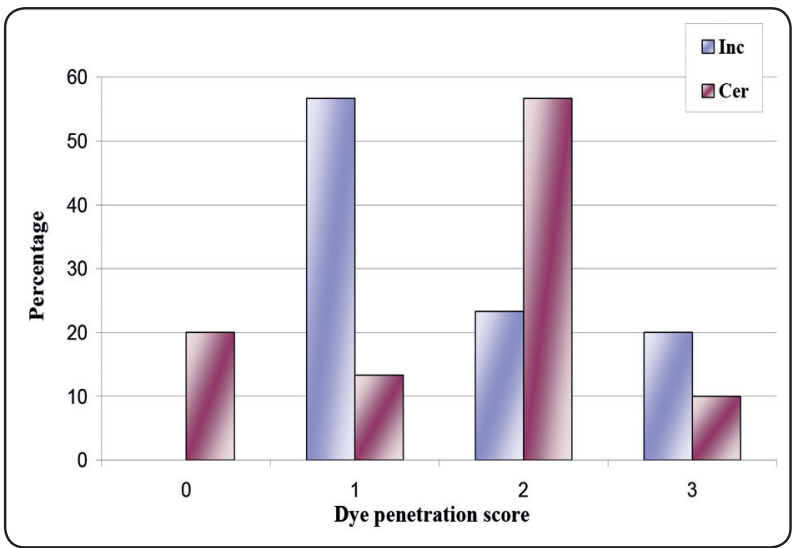

Fig. (3): Chart bar showing the difference in microleakage scores between the incisal and cervical margins of the high speed handpiece group Gr.I in percentage.

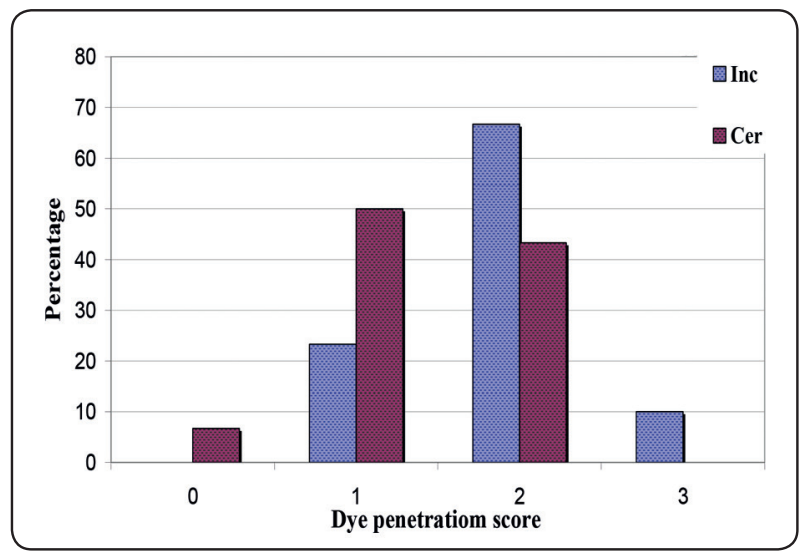

Fig. (4): Chart bar showing the difference in microleakage scores between the incisal and cervical margins of the Er:YAG laser group Gr.II 


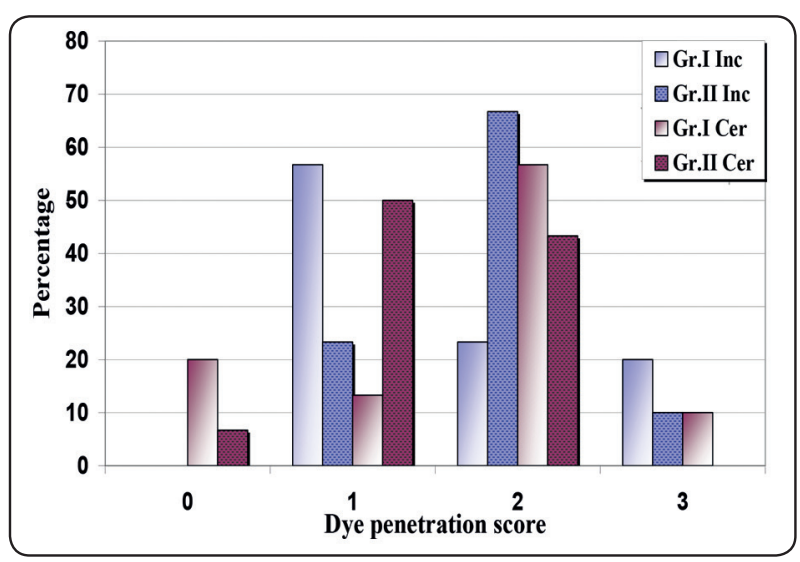

Fig. (5): Chart bar showing the differences in microleakage scores between the incisal and cervical margins of the high speed (Gr.I) compared to the Er:YAG laser group Gr.II

\section{DISCUSSION}

Since the year 1960, studies have never stopped investigating the applicability of laser in caries removal and cavity preparation as a substitution of the high speed dental drill. The Er:YAG laser emitting in the mid-infrared region, of wavelength $2.94 \mu \mathrm{m}$ is found to be efficient and potential in ablation of enamel and dentin with least thermal damage to surrounding unirradiated areas. This laser has a wavelength similar to the absorption wavelength of water $2.94 \mu \mathrm{m}$, causing a water mediated explosive ablation of enamel and dentin which shows a higher ablation than do the thermal vaporization caused by other lasers ${ }^{[16,17]}$.

Er:YAG laser is chosen for this study as it has been investigated as the laser that might replace the dental drill for its unique characteristics. The studies have postulated the parameters of pulse energy, frequencies, spot size, and prepared cavities depth either in enamel or in dentin to be comparable to the conventional high speed bur prepared enamel. Also, clinical studies have tested the working time and cavities shape, the teeth sensitivity, noise and vibration during laser application compared to the speed drill ${ }^{[18]}$.
Microleakage is an important property that has been used in assessing the success of any restorative material used in restoring tooth ${ }^{[19]}$.

Microleakage was evaluated by the dye penetration, which is the commonly applied method to test the sealing of adhesive, tooth-bonded restorations. One of the major dependent factors for microleakage was the luting material ${ }^{[20]}$. The polymerization shrinkage of the luting composite and the difference in thermal expansion coefficient between the luting composite and both the tooth and the porcelain veneer causes stress at the tooth/ luting composite/porcelain interface. Due to this contraction stresses a competition exists between the adhesive forces of the two bonded interfaces: the porcelain/luting composite interface and the luting composite/tooth interface. The interface with the lowest adhesive forces will debond namely the luting composite/tooth interface. Microleakage will occur at this interface breaking this intimate contact and later may then lead to staining, post-operative sensitivity and recurrent caries ${ }^{[21]}$.

The results of the microleakage assessment revealed by the dye penetration scoring between the ceramic veneer and the tooth enamel interface, along the incisal and cervical margins showed that; there were significant difference in the microleakage scores at the incisal margins of the high speed handpiece compared to the Er:YAG laser, and significance comparing the microleakage scores at the cervical margins of both groups (Gr.I) and (Gr.II).

The explanation of decreased microleakage at the cervical margin of laser prepared group can be that; the normal wavy pattern of laser ablated enamel exposing the enamel rod heads with removal of the enamel smear layer which is clearly represented at the middle and cervical thirds of the enamel surface. These irregularities cause the increase in surface roughness that will have a greater surface area which has a great role in decreasing the microleakage (dye penetration) which is clearly identified at the 
cervical margin of laser prepared group having the least microleakage readings ${ }^{[22,23]}$.

Porcelain veneer preparations generally end in this region of aprismatic enamel, which might be largely responsible for the poor marginal sealing reported at the cervical margins of porcelain veneers in vitro prepared by the high speed drill ${ }^{[24]}$.

So the tooth preparations of porcelain laminate veneers by Er: YAG laser decreased the microleakage.

\section{CONCLUSION}

The difference in microleakage assessment between laser and the high speed hand piece specimens was significant and affect the longevity of the porcelain laminate veneers.

\section{REFERENCE}

1. Juliano F, Daniella T, Maria C, Silmara A, Jesus D, Regina G: Comparative study of the dentin/adhesive systems interface after treatment with Er:YAG laser and acid etching using SEM. Las Surg Med.34:385-390;2004.

2. Deleme K, Deman P, Moor R: Microleakage of class V resin composite restorations after conventional and ErYAG laser preparation J Ora Rehab. 2005;32:676-85.

3. Nuray A, Yonca K, Emre O, Ceren O, Erhan F: Microleakage of Class V Cavities with Different Adhesive Systems Prepared by a Diamond Instrument and Different Parameters of Er:YAG Laser Irradiation. Photomedicine and Laser Surgery. 2008;26:585-91

4. Roebuck E, Whitters C, Sauders W: The influence of three energies on the in vitro microleakage of class V compomer resin restorations. Int J Pediatr Dent. 2001;11: 49-56.

5. Dostalova T, Jelinkova H, Hana K, Miyagi M: Er:YAG laser ablation -5- year recall. 2001;4247:1-6.

6. Masahito O, Toro E, Toro M, Hisayoshi T: Comparison of the bond strength of composite resin to Er:YAG laser irradiated human enamel pre-treated with various methods in vitro. Lasers in surgery and medicine 2002;30:351-359.

7. Hossain M, Yamada Y, Nakamura Y, Murakami Y, Tamaki Y, Matsumoto K: A study on surface roughness and microleakage test in cavities prepared by Er:YAG laser ir- radiation and etched bur cavities. Lasers Med Sci 2003;18: 25-31.

8. Andrea N, Peter P, Richard M, Timothy F, Marcelo T, Marcelo G, Giselle M: Evaluation of the Surface Roughness and Morphologic Features of Y-TZP Ceramics after Different Surface Treatments. Photomedicine and Laser Surgery. 2009;27:473-479

9. Sónia E, Raquel O, Manickam S, Rui V, Francesca M, Manuel T: Bond Strength of an Etch-and-Rinse Adhesive to KrF Excimer Laser-Treated Dentin Photomedicine and Laser Surgery. 2010;28:97-102.

10. Chen R, Liu C, Tseng W, Jeng J: Cytotoxicity of three dentin bonding agents on human dental pulp cells. J Dent 2003;31:223-9.

11. Stappert, C, Ozden U, Gerds T, Strub J: Longevity and failure load of ceramic veneers with different preparation designs after exposure to masticatory simulation. J Prosthet Dent 2005;94:132-9.

12. Marco M, Ozcan M: Fracture strength of direct versus indirect laminates with and without fiber application at the cementation interface. J Dent Mater.2006;28:1-7.

13. Kazunori T, Hirohiko F, Yoshikatsu M, Tadashi K, Shigeru $\mathrm{W}$ : Basic study on vibrations during tooth preparations caused by high-speed drilling and Er:YAG laser irradiation. Las. Surg. and Med. 2003;32:25-31.

14. Hossain M, Nakamura Y, Murakami Y, Yamada Y, Matsumoto K: A Comparative Study on compositional Changes and Knoop Hardness measurement of the Cavity Floor prepared by Er:YAG Laser Irradiation and Mechanical bur Cavity. J Clin. Las. Med \& Surg. 2003;21:29-33.

15. Ramachandran P, Baltensperger M, Hans L, Gerold $\mathrm{K}$ : Pulpal response to Er:YAG laser drilling of dentine in healthy human third molars. Las. Surg. and Med. 2003;32:203-09.

16. Aoki A, Ishikawa I, Yamada T, Otsuki M, Watanabe H, Tagami J, Ando Y and Yamamoto H: Comparison between Er:YAG laser and conventional technique for root caries treatment in vitro. J Dent Res. 1998;77: 1404-14.

17. Tokonabe H, Kouji R, Watanabe H, Nakamura Y and Matsumoto K: Morphological changes of human teeth with Er:YAG laser irradiation. J Clin Laser Med Surg 1999;17:7-12.

18. Hossain M, Nakamura Y, Murakami Y, Yamada Y, Matsumoto K: A Comparative Study on compositional Changes 
and Knoop Hardness measurement of the Cavity Floor prepared by Er:YAG Laser Irradiation and Mechanical bur Cavity. J Clin. Las. Med \& Surg. 2003;21:29-33.

19. Wahab F, Shaini F, Morgano S: he effect of thermocycling on microleakage of several commercially available composite Class V restorations in vitro. J Prosth Dent. 2003;90:168-74.

20. Bahillo J, Pinon M, Nogueira J, Biedma B, Patino P, Munoz F, Varela M, Castro N: A comparative study of microleakage through enamel and cementum after laser Er:YAG instrumentation in class V cavity obturations, using scanning electron microscopy. J Clin Laser Med Surg. 2002;20:197-01.

21. Bertrand M, Semez G, Leforestier E, Muller-Bolla M,
Nammour S, Rocca J: Er:YAG Laser Cavity Preparation and Composite Resin Bonding With a Single-Component Adhesive System: Relationship Between Shear Bond Strength and Microleakage. Lasers in Surgery and Medicine 2006;38:615-23.

22. Peumans M, Van Meerbeek B, Lambrechts P, Vanherle G. Porcelain veneers: a review of the literature. J Dent. 2000;28:163-77.

23. Peumans M, De Munck J, Fieuws S, Lambrechts P, Vanherle G, Van Meerbeek B. A prospective ten-year clinical trial of porcelain veneers. J Adhes Dent. 2004;6:65-76.

24. Dhawan P, Prakash H, Shah N. Clinical and scanning microscopic assessments of porcelain and Ceromer resin veneers. Indian J Dent Res 2003;14:264-78. 